\title{
Magalhães e a Química - Reflexos Indiretos ${ }^{i}$
}

$>$

Sérgio P. J. Rodrigues

\author{
Magalhães and Chemistry - Indirect Reflexes. \\ This work refers to some aspects of Fernão de \\ Magalhães' journey, which was continued \\ by Juan Sebastián Elcano, after Magalhães' \\ death. In 2021, five hundred years passed of \\ this journey, which began in 1519 and ended \\ in 1521, one sees that it contributed in various \\ ways to the development of modern culture \\ and science, in particular Chemistry.
}

\begin{abstract}
Este trabalho refere alguns aspetos da viagem de Fernão de Magalhães, a qual foi continuada por Juan Sebastián Elcano, após a morte de Magalhães. Em 2021, passados quinhentos anos dessa viagem que começou em 1519 e terminou em 1521, constata-se que esta contribuiu de várias formas para o desenvolvimento da cultura e da ciência modernas, em particular da Química.
\end{abstract}

\section{Introdução}

Como referem vários autores [1-3], Fernão de Magalhães não pretendia provar que a Terra era redonda (isso já se sabia há muito tempo), nem fazer a viagem de circum-navegação (tinha ordens para voltar pelo mesmo caminho). 0 objetivo da expedição, firmado através de um contrato (capitulação) bem conhecido, era ir até às Ilhas Molucas por oeste, mostrar que estas ilhas estavam do lado castelhano do mundo (dividido pelo tratado de Tordesilhas em 1494), adquirir especiarias e voltar pelo mesmo caminho. Porém, as Ilhas Molucas situavam-se no lado português, Fernão de Magalhães morreu antes de lá chegar e a expedição não deu lucro. No entanto, de qualquer das formas, Magalhães terá sido o primeiro homem a dar a volta ao mundo, embora em duas etapas. De facto, nesta viagem foi de Sevilha até às Filipinas, onde já tinha estado perto numa anterior ocasião ao serviço de Portugal.

Sabe-se muito sobre a expedição de Fernão de Magalhães [1], mas há também bastantes mitos e mal-entendidos à volta desta viagem e dos seus protagonistas. Já foram assinalados alguns deles: os objetivos e os resultados financeiros da viagem. Outros são o papel de Fernão de Magalhães e os pormenores da viagem. Não há qualquer indicação consistente de que Magalhães seria um espião ao serviço do rei de Portugal. 0 que se sabe é que foi considerado na altura um traidor [2,3]. Mas também se sabe que era relativamente normal procurar fortuna noutros países, como terá acontecido nos casos do próprio e de Rui Faleiro, que o acompanhou na preparação da viagem, ao verem recusadas as suas pretensões em Portugal [2,3].

Também há muitos mitos sobre a mortalidade na viagem e sobre o escorbuto, sobretudo na travessia do Oceano Pacífico. É relevante assinalar que a viagem de Magalhães foi muito bem documentada por Antonio Pigaffeta e que Magalhães teve um excelente biógrafo em Stephan Zweig, o que fez com que a expedição tivesse um grande impacto [1]. Também há excelentes trabalhos de divulgaçãa sobre a viag’em de Magalhães e sobre os seus protagonistas [2-9].

A expedição era verdadeiramente internacional (espanhóis, dos quais bastantes andaluzes, bascos e asturianos, portugueses, italianos, dos quais muitos genoveses, franceses, dos quais bastantes bretões, gregos, flamengos, alemães, africanos, um goês, um malaio e mestiços) [1,2] e havia uma parte de investimento privado (a coroa espanhola financiou $77 \%$ dos custos, sendo os restantes $23 \%$ assumidos por privados) [2,3].

Há vários momentos em que a política e a sorte conduziram as descobertas marítimas, como é bem conhecido. E é possível assinalar momentos em que ocorreram avanços científicos sem serem referidas as contribuições dos navegadores portugueses. Por exemplo, a proposta dos métodos mecânicos para medição das longitudes costuma ser atribuída aos ingleses, mas já os portugueses e outros navegadores usavam vários destes métodos [10]. Em particular, os métodos astronómicos e mecânicos usados por Magalhães, e já antes pelos navegadores portugueses, permitiam medir razoavelmente a longitude. A expedição de $\mathrm{Ma}$ - 
galhães tinha como objetivos verificar que as Molucas estariam do lado espanhol do tratado de Tordesilhas, mas pensa-se que o navegador percebeu que afinal estavam do lado português quando chegou às Filipinas, que estavam mais ou menos à mesma longitude [2].

A relação entre o escorbuto e os alimentos frescos era provavelmente também conhecida dos navegadores portugueses. É possível verificar este facto de forma indireta em vários documentos da época e na famosa obra "Peregrinação" de Fernão Mendes Pinto, em que se refere que assim que os navegadores atracavam nalgum local procuravam frutas e lhes serviam sumos. Para a história ficou que terá sido o capitão Cook e o seu médico Lindt que descobriram a importância do consumo de produtos frescos usando o método científico [11], mas há várias formas de analisar esta questão. É, no entanto, importante referir que foram essencialmente os franceses e os ingleses a desenvolver métodos de publicação e discussão dos resultados científicos que se tornaram regra na ciência.

Chandeigne refere 146 nomes de marinheiros que morreram na viagem de Magalhães, tendo esta à partida 237 pessoas [1]. Isto mostra que não houve uma mortalidade tão exagerada como se refere. Embora só tivesse chegado uma nau com 18 sobreviventes a Sevilha, muitos marinheiros regressaram de outra forma (desertaram ou foram feitos prisioneiros pelos portugueses antes de voltar) [1]. Além da indicação de escorbuto, se considerarmos que todas as mortes que não têm indicação da causa (ou seja, tirando as execuções judiciais, os ferimentos, os afogamentos e várias doenças que não o escorbuto, entre outras) seriam devidas ao escorbuto (o que é manifestamente exagerado), há 79 mortes devido a esta doença, ou seja $54 \%$ dos óbitos. Considerando apenas o período em que é referido que o escorbuto dizimou a tripulação, observa-se a ocorrência de 34 mortes, o que corresponde a $23 \%$ (e mesmo neste caso pode ser exagerado). Ou seja, embora o escorbuto fosse terrível, incapacitante e doloroso, muitas vezes não causava a morte e era evitável. Portanto, os números mostram que é excessivo referir que as tripulações pereceram devido ao escorbuto. É curioso ser referido que a tripulação foi dizimada pelo escorbuto apenas à saída das Molucas. Na travessia do Oceano Pacífico, Chandeigne [1] refere 11 mortos. Ou seja, não foi na travessia do Pacífico que ocorreram mais mortes, mesmo que se pense que todas elas seriam devidas ao escorbuto. Este facto mostra de forma indireta que Fernão de Magalhães sabia o que fazer para minimizar esta doença. Ou então, talvez tivesse tido sorte e Elcano não soubesse ou tenha tido azar...

Estes resultados em relação ao escorbuto podem ser vistos como danos colaterais do amadorismo que rodeou o início dos descobrimentos marítimos. E também de uma certa e natural reserva. Mas não se faça disso toda uma teoria. Embora os navegadores portugueses possam ter sabido mais do que se pensa, em particular com base no seu conhecimento empírico, não se encontram muitos registos. Mas, atualmente, a teoria do segredo sistemático de Jaime Cortesão [12] foi rebatida por vários autores [13], mas ainda é por vezes evocada [14], mesmo sabendo-se bastante sobre as condições das viagens marítimas (e.g. [15]). Os portugueses eram supostamente avessos a escrever e desconfiados em relação à escrita. D. João de Castro e Garcia da Orta pagaram por isso, o primeiro queimado depois de morto e o segundo tendo de fugiri. A inquisição e as perseguições acabaram por contribuir negativamente, infelizmente. Essa falta atual de registos escritos, associada, talvez, a várias dominações, invasões e guerras que se deram ao longo da história, fizeram com que muitos possíveis feitos dos portugueses tenham sido fantasiados ou esquecidos.

Outro exemplo foram as viagens dos jesuítas. Os padres portugueses foram os primeiros a chegar e a escrever sobre os Himalaias, mas, depois de um hiato, surgiram os ingleses. Neste caso, entram outros fatores, como a expulsão dos jesuítas e o facto da escrita destes padres ter objetivos muito particulares. Somando a perseguição aos interesses dos jesuítas, os seus feitos estavam votados a ser esquecidos.

Com a Índia e o chá passou-se algo parecido, mas com muita fantasia pelo meio. Uma princesa portuguesa casou com um rei inglês e teria supostamente como dote a Índia e o chá. Não é bem assim, Catarina de Bragança gostava de beber chá, parece. No século XVI os portugueses dominavam boa parte da Índia e as Molucas, mas foram lentamente perdendo o domínio para outros. 0 mesmo se passou com África e com as expedições científicas. Além das fantasias patrióticas já referidas, os ingleses convenceram muitos intelectuais portugueses de que estes nada sabiam e que nada faziam, o que não deixa de ser interessante. Se, por um lado, havia indignações patrióticas, por outro os portugueses acreditavam serem inferiores (como nação). Para isso também concorreram a suposta aversão à escrita, a pilhagem pelos franceses e ingleses, as perseguições religiosas, mas sobretudo algum azar. Os portugueses não deixaram bem documentados os seus feitos nem criaram escola.

Obviamente, foram os franceses e os ingleses, como já foi referido, que aperfeiçoaram a publicação científica, que melhoraram muito os métodos usados, que deram o início à revolução industrial, entre outras coisas. Nada disso está em causa, mas a abertura ao desconhecido e o conhecimento baseado na experiência são devidos às navegaç̧ões iniciadas pelos portugueses.

Esta longa introdução parece não ter relação com a Química, mas tem. 0 desenvolvimento desta ciência, embora tendo sido relativamente tardio em relação ao da física e ao da astronomia, por exemplo, acaba por dever muito às descobertas marítimas. 


\section{Química e a viagem de Fernão de Magalhães}

Na Figura 1 pode ver-se a repartição do mundo que se seguiu ao tratado de Tordesilhas e a viagem de Magalhães realizada ao redor do mundo ao longo de três anos e de cerca de 69800 quilómetros [1]. Estão assinalados os percursos seguidos por Magalhães e 0 fim da viagem de circum-navegação terminada por Elcano. Na mesma imagem é indicado o número de prémios Nobel da Química por nacionalidade. Como se pode verificar, não há aparente relação entre eles. Embora a maioria dos prémios Nobel pareça estar do "lado" português, é também óbvio que a maioria destes se encontra na "velha" Europa, havendo poucos no Novo Mundo. Encontramos um número razoável (15) nos Estados Unidos da América, um no Canadá e outro no Japão (que se estende pelas duas partes). Vemos assim que a viagem não originou prémios Nobel nos locais onde passou, embora tenha contribuído para espalhar a ciência como a conhecemos hoje a todo o mundo.

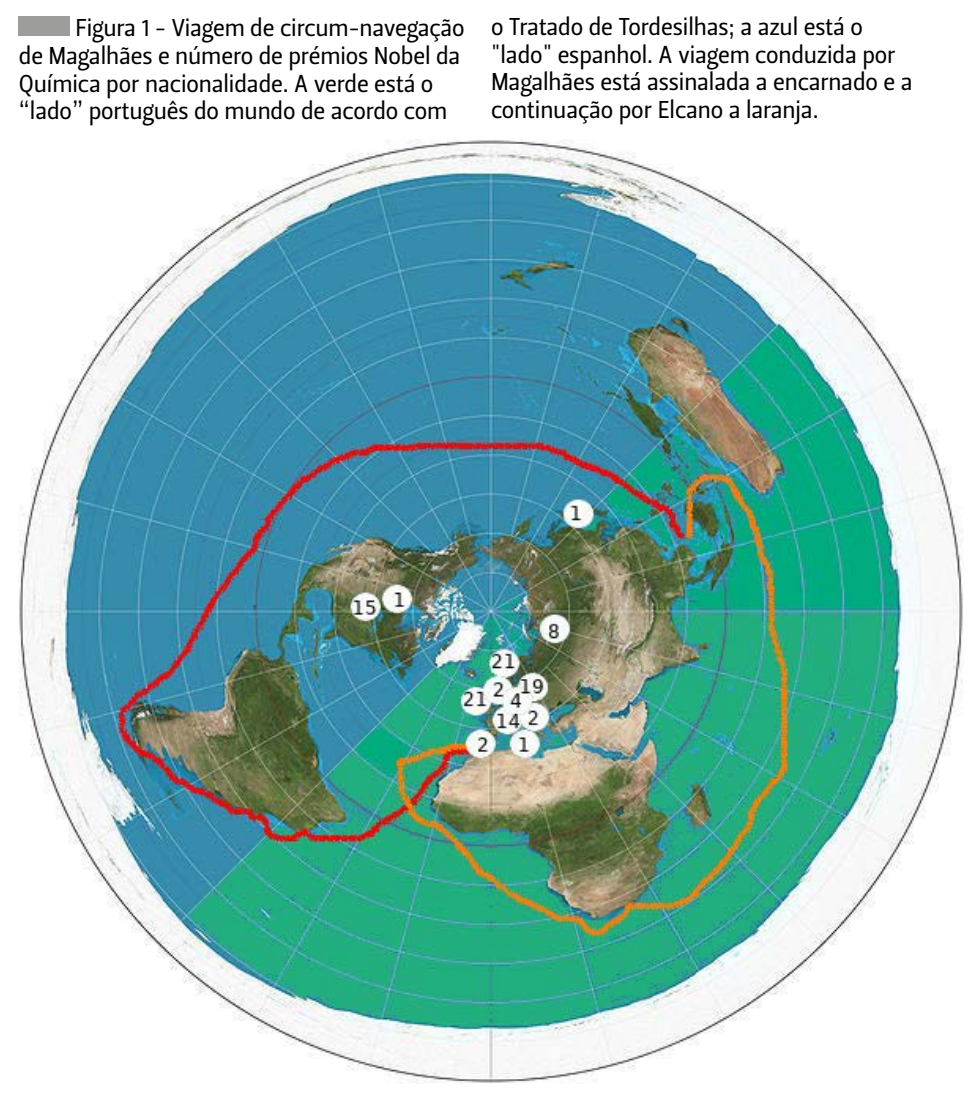

Magalhães não esteve relacionado com a descoberta de nenhum elemento químico, exceto no que concerne à ideia de que é possível descobrir e inventar coisas novas. Os descobrimentos e as viagens marítimas acabaram por ter uma grande influência no desenvolvimento da ciência, em particular em quatro aspetos: (1) os comentários antigos e atuais podem ser importantes, mas têm de ser vistos com pensamento crítico; (2) no universo podem ser descobertas e inventadas coisas novas e que estas são semelhantes noutros locais e seguem as mesmas leis; (3) para se confirmar um facto, tem de se observar e fazer experiências sobre ele, não bastando comentar; (4) o conhecimento deve ser escrito e aberto para ser verificado (o que inicialmente possa ser uma vaidade e uma forma de afirmação das nações, acaba por se tornar uma das pedras de toque da ciência moderna). É por isso que, por exemplo, existe ceticismo em relação a informações fantasistas (gigantes e outros monstros), mas há abertura em relação à descoberta de novas plantas e animais e que consideremos normal fazer investigação aqui e no outro lado do mundo e comunicar os resultados, e muitos outros exemplos de recolha e partilha de informação científica que hoje nos parecem normais, mas na altura não o eram.

Voltando à baixa incidência de escorbuto na travessia do Oceano Pacifico da expedição liderada por Magalhães, uma das explicações para haver poucas vítimas desta doença seriam as conservas feitas em vinagre, no Estreito de Magalhães, de um aipo selvagem rico em vitamina C [1]. Não é muito claro de que aipo se tratava, mas há algumas propostas, provavelmente Aipum prostratum $[16,17]$. Na expedição do capitão Cook batizaram um aipo como Aipum antiescorbuticum por ter ação antiescorbútica. Infelizmente, as conservas em vinagre fazem desaparecer rapidamente a vitamina C e, portanto, para esse resultado devem ter concorrido outras contribuições ou circunstâncias. Em qualquer dos casos, o que se sabe é que a mortalidade foi muito baixa. Atualmente, o que se faria seriam estudos experimentais, preservando as cobaias humanas.

Embora o vinagre de vinho ou de cidra tenha muito pouca quantidade de vitamina C e façam desaparecer rapidamente o ácido ascórbico dos produtos alimentares que são conservados na sua presença, o vinagre de palma apresenta uma razoável quantidade desta molécula (até aumenta a sua concentração em relação à existente no produto original) e provavelmente não elimina a vitamina C dos alimentos nele conservados (e.g. [18-20]). No Brasil obtinham-se vinagres de várias plantas e pode vir daí o vinagre mais rico em vitamina C e a sua ação na luta contra o escorbuto, se consumido durante a expedição.

\section{Resultados de longo prazo da viagem de Fernão de Magalhães}

Escreve Vitorino Magalhães Godinho em 1990 que "sem os descobrimentos não se teria industrializado o mundo" [21]. A afirmação é muito pertinente, embora algo tautológica como toda a história que busca antecedentes, mas há vários aspetos da ciência e da tecnologia a considerar. A autoria e a aplicação são muito voláteis. Se uma pessoa ou nação não descobre ou inventa, outras vão fazê-lo, mais tarde ou mais cedo. E uns podem beneficiar das descobertas e invenções dos outros, como é óbvio. A 
história está cheia destes casos. Claro que há descobertas e invenções (processos e moléculas que tiveram papéis decisivos na história do mundo [22]) com marcas pessoais e nacionais na ciência e na tecnologia, até por serem atividades humanas, mas a regra é muito mais geral.

A viagem de Magalhães teve grande influência na cultura. Há uma revista científica, uma universidade, lugares geográficos e astronómicos, ruas e praças, estátuas, está indicada para a UNESCO como património da humanidade, há sondas espaciais e marítimas, equipamentos vários, um computador, escolas, inspirou e inspira programas educacionais, concursos científicos e projetos, o que demonstra bem a influência no desenvolvimento da Ciência e da Tecnología e o seu papel na motivação e inspiração das gerações posteriores. No que concerne à tabela periódica, embora não seja diretamente relacionado, é relevante referir a ideia de circularidade e continuidade expressa visualmente pelas tabelas circulares $[23,24]$.

\section{Conclusão}

A viagem de Fernão de Magalhães teve grande influência na cultura, como foi referido. Esta viagem está, no entanto, rodeada de mitos e mal-entendidos. Nada indica que Magalhães fosse um espião ao serviço de Portugal e

\section{Notas}

i Este trabalho é baseado numa palestra realizada pelo autor nas comemorações do Ano Internacional da Tabela Periódica (AITP).

\section{Referências}

[1] M. Chandeigne (ed.), "A viagem de Fernão de Magalhães: a relação de Antonio Pigafetta (1519-1522)", Imprensa Nacional Casa da Moeda, Lisboa, 2020.

[2] L. F. R. Thomaz, "O drama de Magalhães e a volta ao mundo sem querer", Gradiva, Lisboa, 2018.

[3] J. M. Garcia, "Fernão de Magalhães - Herói, Traidor ou Mito", Manuscrito, Lisboa, 2018.

[4] G. Cadilhe, "Nos passos de Magalhães", Oficina do Livro, Lisboa, 2008.

[5] J. M. Garcia, "Fernão de Magalhães - Lisboa e o início da Mundialização", Câmara Municipal de Lisboa, 2018

[6] Visão História, "Fernão de Magalhães: A primeira volta ao mundo", fevereiro de $\mathbf{2 0 2 0}$.

[7] J. P. O. Costa, "National Geographic" (edição portuguesa), setembro de 2019, pp. 2-23.

[8] E. Lira, "National Geographic" (edição portuguesa), outubro de 2019, pp. 74-88.

[9] P. O. Simões, História 2019, 22, 62-73.

[10] F. B. Figueiredo, Gaz. Mat. 2014, 173, 26-35. gazeta.spm.pt/fichaartigo?id=453.

[11] R. Collier, Can. Med. Assoc. J. 2009, 180, 23-24. DOI: 10.1503/cmaj.081879.

[12] J. Cortesão, "A política de sigilo nos descobrimentos", Comemorações do Quinto Centenário da Morte do Infante D. Henrique, Lisboa, 1960.

[13] F. C. Domingues, Mare Liberum, 1990, 1, 105-116.

[14] M. S. Rosa, "Portugal e o segredo de Colombo", Alma dos Livros, Lisboa, 2019

[15 F. C. Domingues (Coord.), "Navios, Marinheiros e Arte de Navegar 15001668", Academia da Marinha, Lisboa, 2012. temos a certeza de que o objetivo da viagem não era a circum-navegação da Terra. A viagem não deu lucro e o escorbuto não terá tido um papel decisivo na morte dos marinheiros, sobretudo na travessia do Oceano Pacífico. Esta viagem fez parte de todo um ambiente que propiciou o avanço da ciência moderna, e também da Química, como a conhecemos hoje. Mostrou que há algo de novo para descobrir e inventar e que a descoberta acontece, muitas vezes, por acaso, quando se investigam outros assuntos; que as leis da física e da química se aplicam em todos os locais e não são arbitrárias; que o método experimental ligado a teorias que se vão confirmando é fundamental; que a informação e disseminação dos resultados é aditiva, avançando a ciência por construção a partir dos resultados anteriores, e que as teorias anteriores são sempre passíveis de revisão. Em muitos casos podem ser integradas como casos particulares, outras vezes não se ajustam à realidade e são abandonadas.

\section{Agradecimentos}

O Centro de Química de Coimbra (CQC) é apoiado pela Fundação para Ciência e a Tecnologia (FCT), Portugal, através dos projetos UIDB/00313/2020 e UIDP/00313/2020. 0 autor agradece as sugestões e comentários dos revisores e editores.

16] P. V. Gómez (Ed.), "Em búsqueda de las especies. Las plantas de la expedicion Magallanes-Elcano (1519-1522)", CSIC, Madrid, 2020

[17] T. N. Carvalho, Magallánica 2020, 7, 288-314. fh.mdp.edu.ar/revistas/ index.php/magallanica/article/view/4839.

[18] D. K. Salunkhe, S. K. Pao, G. G. Dull, W. B. Robinson, CRC Crit. Rev. Food Tech. 1973, 4, 1-38. DOI: 10.1080/10408397309527152.

[19] S. Ghosh, R. Chakraborty, A. Chatterjee, U. Raychaudhuri, J. Inst. Brew. 2014, 120, 550-558. DOI: 10.1002/jib.153.

[20] T. Xia, B. Zhang, W. Duan, J. Zhang, M. Wang, J. Funct. Food. 2020, 64, 103681. DOI: 10.1016/j.jff.2019.103681.

[21] V. M. Godinho, "Mito e Mercadoria, utopia e prática de navegar - séculos XIII-XVIII", Difel, Lisboa, 1990.

[22] J. P. Le Couteur, J. Burreson, "Napoleon's buttons: 17 molecules that changed history", Jeremy Teacher, New York, 2004.

[23] G. N. Quam, M. B. Quam, J. Chem. Educ. 1934, 11, 288-297. DOI: 10.1021/ ed011p288

[24] E. Scerri, "The Periodic Table: Its Story and Its Significance" $2^{\text {nd }}$ ed., Oxford University Press, 2019.

\section{$>$}

\section{Sérgio P. J. Rodrigues}

Centro de Química de Coimbra, Universidade de Coimbra.

Sérgio P. J. Rodrigues é professor auxiliar no Departamento de Química da Universidade de Coimbra, Portugal. A sua área de investigação é a química teórica e computacional e as suas aplicações em química ambiental, astroquímica e química medicinal.
Tem também interesse pelo ensino e história da química, assim como pela divulgação e comunicação de ciência. Em 2019 fez parte da comissão das comemorações do Ano Internacional da Tabela Periódica (AITP) organizada pela SPQ.

spjrodrigues@ci.uc.pt ORCID.org/0000-0002-4640-7039 